SEBASTIAN CARES PERALTA

ESCUELA DE DISEÑO

FACULTAD DE ARQUITECTURA Y URBANISMO

UNIVERSIDAD DE CHILE

SEBASTIAN.CARES@UG.UCHILE.CL
Cómo citar: Cares, S. (2017). Acercamientos a

la educación del color en el diseño gráfico de

la Universidad de Chile desde sus orígenes a

la actualidad. Una reseña histórica.

RChD: creación y pensamiento, 2(3), 1-8.

DOI: $10.5354 / 0719-837 \times .2017 .47703$

\section{Acercamientos a la educación del color en el diseño gráfico de la Universidad de Chile desde sus orígenes a la actualidad. Una reseña histórica}

Approaches to Color education in Graphic Design at the University of Chile. A historical review, from its origins to today

Resumen: La enseñanza artística ha estado incluida en el sistema pedagógico chileno desde el siglo XVIII. Sin embargo, el Diseño Gráfico como disciplina proyectual no logra concretarse en Chile hasta la segunda mitad del siglo $X X$, abriendo paso entre escuelas de artes y escuelas de oficios a lo largo de la historia. De esta manera, esta disciplina proyectual sentó finalmente sus bases en la Escuela de Artes Aplicadas (EAA) que funcionó entre 1928 hasta 1968, institución en la cual se formaron profesores que participaron en la fundación de las escuelas de diseño tal como la Universidad de Chile, y que, por tanto, suponen una formación de color con un enfoque desde las artes plásticas por al cauce natural de la formación de la EAA. Sin embargo, las necesidades en relación al color que propuso el diseño como nueva disciplina, llevó a que profesores de su plantel docente se empezaran a interesar por el estudio del color a modo de complementar sus saberes adquiridos. De esta forma, algunos profesores se han especializado en el tema y han desarrollado cursos dedicados a tratar solamente el fenómeno de color, contribuyendo de manera significativa a la formación de estudiantes de diseño a lo largo de sus carreras.

Palabras clave: Color, Diseño Gráfico, Enseñanza, Universidad de Chile. 


\section{Introducción}

En el círculo académico chileno existe una gran preocupación por la actual formación de color debido a que no se le estaría dando la importancia suficiente a esta materia en las aulas nacionales. Sin embargo, a pesar de este interés mostrado, no ha habido investigaciones que aporten en este tema para entender como esta temática se ha desenvuelto en las aulas nacionales $y$, con ello, entender el origen de lo que se está enseñando sobre color hoy en día. Sin embargo, esto no es una discusión nueva, ya que así lo clarifica John Gage, en su libro Color y Cultura (1993), donde expresa:

"Casi todo el mundo se ha interesado por el color, pero rara vez de una perspectiva unitaria. [...] Lo que me interesa es precisamente entender cómo se ha llegado a esta fragmentación, qué es lo que ha impedido que investigadores inteligentes y sensibles hayan llegado a una adecuada comprensión de su materia de estudio, porque gran parte de lo que se ha escrito y se sigue escribiendo sobre el color no nos convence. Debemos enfocar mejor la materia desde una perspectiva histórica, pese a que la propia noción de una historia del color pueda en principio parecer paradójica".

Es por esta razón que esta investigación busca dar luces de cómo se ha realizado la enseñanza del color en esta disciplina mediante una exploración retrospectiva a los orígenes del diseño gráfico en la Universidad de Chile, a modo de contribución para mejorar el panorama local de la formación y entendimiento sobre este tema. Por tanto, se llevó a cabo una revisión bibliográfica sobre los orígenes del diseño gráfico, y de cómo este logró constituir su condición de disciplina proyectual independiente de la formación en color. Para conseguir un mayor acercamiento con los hechos históricos, también se entrevistó a protagonistas relevantes a la enseñanza de color, para que con sus testimonios nutran y complementen este relato.

\section{Desarrollo. Inicios de la educación artística en Chile}

Aunque sabemos que la enseñanza artística ha estado incluida en el sistema pedagógico chileno desde el siglo XVIII (Biblioteca Nacional de Chile, s.f.), el arte en Chile tiene una historia previa. Los primeros rasgos artísticos en territorio chileno se presentaron mucho antes de la llegada de los colonos españoles en 1541 (Pereira, 1965) donde las culturas que ya habitaban estas tierras poseían toda una gama de expresiones de arte y de utilización de color, las cuales eran traspasadas de generación en generación (Museo Chileno de Arte Precolombino, s.f.). Posterior a la llegada de los españoles, ya el periodo colonial, donde se inicia el sincretismo cultural entre europeos e indígenas, el quehacer intelectual y educativo estuvo circunscrito al ámbito de la iglesia, la cual tenía reservada la función de asignar títulos y grados académicos (Biblioteca Nacional de Chile, s.f.). El ámbito artístico por fuera de lo hermético que era la enseñanza de las iglesias radicaba en la organización artesana basada en el opus manu factum, que fue la base artística de la primera época de la colonia (Pereira, 1965) y que continuó por mucho tiempo. Las primeras universidades chilenas, de modo natural, surgieron al amparo de órdenes religiosas (Biblioteca Nacional de Chile, s.f.), sin embargo, con las primeras ideas republicanas a final de siglo XVIII y con el crecimiento económico, el contexto mejoró, haciéndolo propicio para las artes visuales y desvinculándolo del servilismo religioso (Biblioteca Nacional de Chile, s.f.). Con el paso al siglo XIX, vino la fundación 
de la Universidad de Chile en 1843 como principal casa de estudios superior del país, de carácter público, laico y nacional en concordancia con la Constitución de 1833, que aseguraba el orden y la institucionalidad por parte de las autoridades que se preocuparon por otorgar al país un sistema educacional acorde a las necesidades de la nueva República (Biblioteca Nacional de Chile, s.f.). Si bien durante la segunda mitad del siglo XIX se centró en la formación de jóvenes hacia el ámbito artístico o técnico (Castillo, 2010), al llegar el siglo XX la discusión se enfocó en la necesidad de reorientar la enseñanza artística bajo una finalidad mucho más práctica, lo que desembocó en que en 1906 se fundara la Escuela de Artes Decorativas, institución dependiente de la Escuela de Bellas Artes (Castillo, 2010). Esta última y sus entidades a cargo, incluyendo la recién fundada Escuela de Artes Decorativas, pasaron a depender definitivamente de la Universidad de Chile dos años más tarde, hecho que conllevó a que en 1910 se trasladara nuevamente y fusionara sus dependencias con el Museo de Bellas Artes (Universidad de Chile, s.f.).

\section{Escuela de Artes Aplicadas, la antesala del Diseño Gráfico}

El consejo de la Universidad de Chile, presidido por su Rector Domingo Amunátegui Solar (1880-1946), aprobó en 1914 un reglamento para la Escuela de Bellas Artes que establecía que esta escuela tendría una sección destinada al arte puro y otra al arte aplicado a la industria, aunque los años venideros esta sección tuvo una precaria actividad hasta 1928. Sin embargo, con el afán de rescatar el grupo de cursos que comprendía la sección de artes decorativas en decadencia, el director de la Escuela de Bellas Artes, el pintor y músico Carlos Isamitt (18871974), llevó a cabo una importante reforma a la enseñanza artística de ese entonces, la cual origina el reconocimiento de la Escuela de Artes Aplicadas (EAA) en 1929 como una entidad independiente a la Escuela de Bellas Artes (Castillo, 2010). La EAA, bajo la dirección de su principal gestor José Perotti (1898-1956), tuvo por objetivo la formación profesional de artífices y artesanos, generando talleres artísticos prácticos en el país, y cooperando con la industria en general (Soto Veragua, 2008). Sin embargo, debido a la crisis que generó la falta de financiamiento ese mismo año, toda referencia a las artes comenzó a circunscribirse a la Universidad de Chile (Soto Veragua, 2008) y, por este motivo, al año siguiente se forma la Facultad de Artes Plásticas de la Universidad de Chile, al juntarse en una sola institución diversas entidades creadas para la promoción del arte, entre ellas la Escuela de Bellas Artes, el Conservatorio Nacional de Música y Declamación, la Escuela de Cinematografía Educativa, el Departamento de Extensión Artística (Universidad de Chile, s.f.) y la EAA (Soto Veragua, 2008). Dentro de los incipientes talleres que se impartían en 1933 y 1934 están: Artes del fuego, donde impartían clases de fundición, cerámica, esmalte sobre metales, y vitrales; Artes de los metales donde se enseñaba hierro forjado, repujado en metal y fundición; Artes textiles que impartían clases de elaboración y diseños de motivos para géneros, estampado textil, gobelinos, teñidos, telas a telar y alfombras a telar; Artes de la madera donde enseñaban ebanistería, decoración de interiores, xilografía y un curso de química industrial y Artes gráficas con clases de tipografía, afiches, grabado, impresión y encuadernación (Soto, 2008). Este último taller, es el puntapié inicial de la especialidad que posteriormente conoceremos como Diseño Gráfico, y es precisamente en la EAA donde se formarán grandes profesores que se dedicarán a la enseñanza de esta disciplina en las aulas de las posteriores escuelas de diseño, teniendo gran influencia desde la plástica debido a la gran convivencia que tuvo la EAA con las 


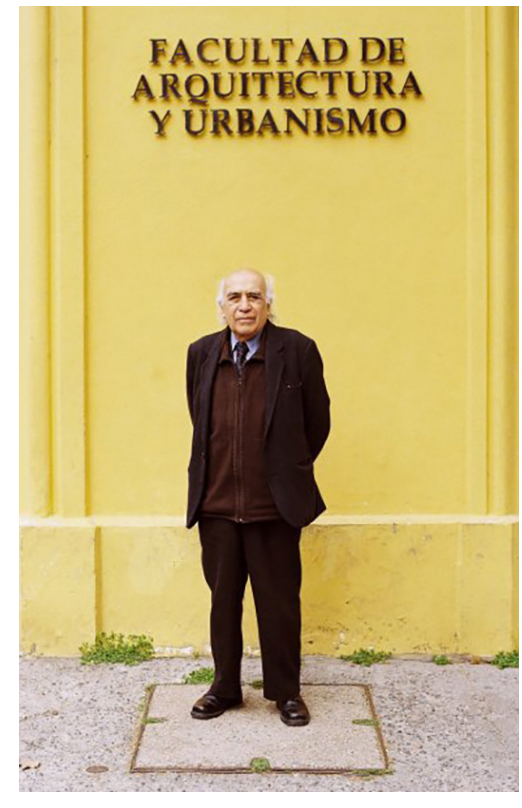

Figura 1. Profesor Arturo Molina. Fuente: Fotografía de Francisco Martínez. escuelas de Bellas Artes y al resto de las entidades subscritas a la Universidad de Chile y que fomentaban las artes. Incluso en 1937 es el mismo director de la EAA, el Sr. José Perotti, quien obtiene una beca para viajar a Alemania donde realizó estudios de color además de perfeccionarse en otras materias (Museo Nacional de Bellas Artes, s.f.), volviendo a Chile con nuevos contenidos para aportar. Sin embargo, esta formación siempre estuvo ligado al campo de las bellas artes. Al inicio de la década de los 50, la formación de color en la EAA estaba principalmente inserta en la asignatura "Composición", la cual estaba a cargo de Nora Pizzi (Castillo, 2010). No obstante, en otras asignaturas igualmente se corregía su uso en proyectos (Molina A., comunicación personal, 14 de septiembre de 2017). Esta asignatura no solo estaba orientada a contenidos sobre color, sino, también a otros módulos que la componían, tales como forma, equilibrio, entre otras, y siempre desde su enfoque desde las bellas artes (Molina, 2017). Posteriormente, Arturo Molina, ex alumno de este curso de composición y egresado en 1962 como Artífice con mención en Decoración de Interiores, se dedicó a labores docentes en la EAA donde también fue adquiriendo conocimientos sobre el color como ciencia y teoría en base a libros que adquirió, tales como The Art of Color de Johannes Itten, Color, Form and Space de Faber Birren o Interaction of Color de Josef Albers (Molina, 2017). Esto se debió a que para este profesor no fue del todo suficiente el enfoque meramente decorativo que se enseñaba sobre el color en la EAA y que provenía por tradición desde la Escuela de Bellas Artes, por lo que estaba lejos de satisfacer las necesidades de la nueva disciplina en formación (Molina, 2017). Su crítica e interés por este tema, lo llevó a tener un aprendizaje autodidacta e inaugurar la asignatura de Teoría de Color en 1964, donde trató el color desde diversas perspectivas tanto físicas, químicas, psicológicas, compositivas, entre otras (Molina, 2017). Esto sería un gran aporte para la carrera de diseño que se encuentra en gestación en este periodo, debido a que otorga una mirada al estudio del color mucho más orientada a un usuario y/o a un propósito sin dejar de lado lo estético y decorativo (Molina, 2017). En la EAA, según recuerda el profesor Waldo González, trabajaron con lápiz de color, lápiz grafito, tinta china, plumones y témperas, así como trabajaban con collage, lápices de fieltro y recortes de papel (Castillo, 2010). Sin embargo, Arturo Molina trabajaba además con proyectores para exponer la teoría de color luz y experimentar con ella (Molina, 2017).

\section{Formación de la Escuela de Diseño Gráfico en la Universidad de Chile}

A partir de 1968, el movimiento de reforma universitaria cambia la estructura de escuelas por una estructura de departamentos, y en la Escuela de Bellas Artes se generan los departamentos de Plástica, Teoría e Historia de las Artes Plásticas y Pedagogía. En la Escuela de Canteros se genera el Departamento de Arte Público y Ornamental; y en la EAA se organizan los departamentos de Artesanía y Diseño constituyéndose en el nuevo local de Cerrillos, donde compartió instalaciones con la Escuela de Arquitectura (Soto Veragua, 2008). Con este nuevo cambio, todos los saberes de la EAA pasaron a sentar las bases de las posteriores escuelas de diseño.

En 1972, debido al Plan Chile-California, donación hecha por la Fundación Ford, el profesor Molina viaja a la sede de Berkeley de la Universidad de California en Estados Unidos de América (Molina, 2017). Es aquí donde conoce a personas que trabajan el color y pertenecían a la Inter-Society Color Council, organización en la cual fue invitado a ser miembro. Este hecho le proporcionó al profesor Molina estar informado sobre los últimos estudios y actividades que 


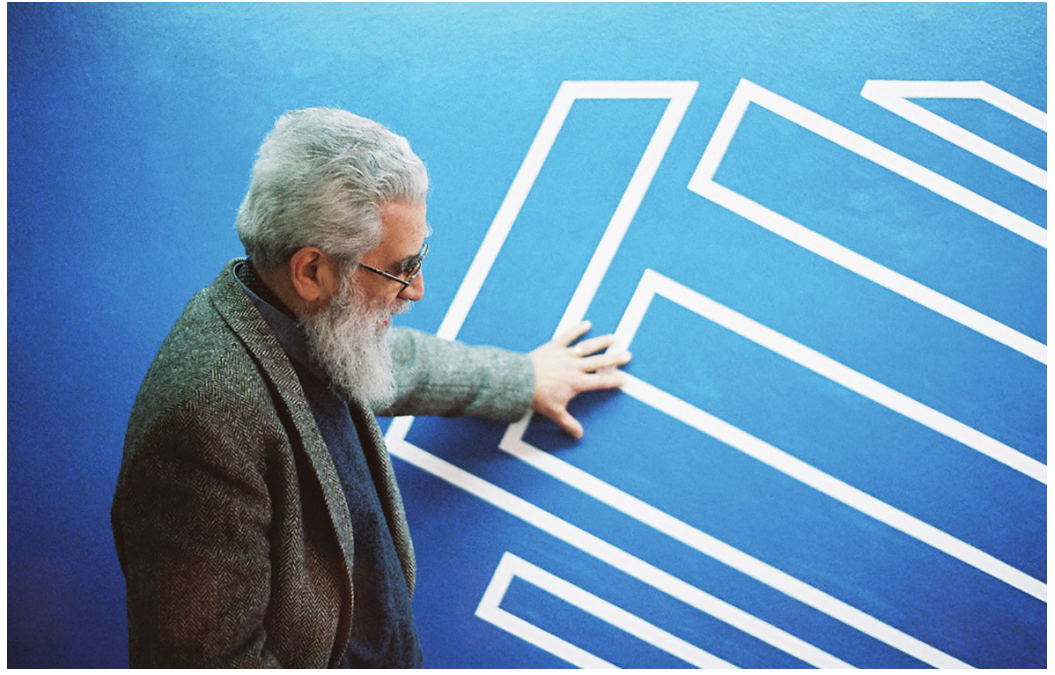

se realizaban año a año en torno al color, lo cual nutrió su formación y sus actividades docentes en este tema (Molina, 2017).

En el año 1976, debido a la influencia del gobierno militar, se tomaron medidas en la Universidad de Chile que llevaron a reorganizar las sedes de Santiago. La Escuela de Diseño, con todas sus menciones, pasó a depender de la Facultad de Arquitectura, para luego trasladarse en 1977 a las dependencias que actualmente ocupa en calle Marcoleta esquina Portugal (Soto Veragua, 2008), donde el hecho de pasar a tener entre cuatro y cinco mil metros cuadrados a tener menos de mil, provocó la mutilación de la carrera y su implementación (Soto Veragua, 2008). Con ello se cerraron Paisajismo y Textil e Industria, que estaba a prueba, no tuvo la posibilidad de ser abierta en la universidad, continuando sólo Gráfica, Muebles e Interiores (Soto Veragua, 2008). En 1978, debido al cierre del ingreso de alumnos nuevos y, además, a la disminución significativa de su plantel académico, se cierra la escuela de diseño en esta institución en diciembre de 1980, ya que el 7 de enero de 1981 la dictadura militar anuncia una nueva reforma universitaria que dejaría a la Universidad de Chile solo con doce carreras. En dicha reforma, el decreto con fuerza de ley $\mathrm{N}^{\circ} 2$ del Ministerio de Educación Pública fija normas sobre universidades:

“Dentro de 90 días contados desde la publicación de la presente ley, Los rectores de las actuales universidades propondrán al presidente de la República un programa de reestructuración de las respectivas corporaciones de modo que, cada una de ellas, cuente con un número racional de alumnos que le permita cumplir adecuadamente con sus finalidades propias. Para los fines indicados en el inciso anterior, dicha proposición se deberá consultar, si procediere, la división de las universidades actualmente existentes. Las universidades $u$ otras entidades que se deriven de la división consecuente no podrán hacer referencia en su nombre al de una universidad existente." De esta forma, la Universidad de Chile sufrió el desmembramiento del Pedagógico, del Tecnológico y de las trece sedes que eran de la universidad en diferentes ciudades del país, quedándose solamente con las sedes de Santiago. Así, las sedes de regiones se fusionaron principalmente con las sedes de la Universidad Técnica del Estado (UTE) para formar las universidades locales (Soto Veragua, 2008).
Figura 2. Profesor Hugo Rivera-Scott. Fuente: Fotografía de Dai liv. 
Figura 3. Profesora Ingrid Calvo Ivanovic. Fuente: Fotografía de Jocelyn Muñoz.

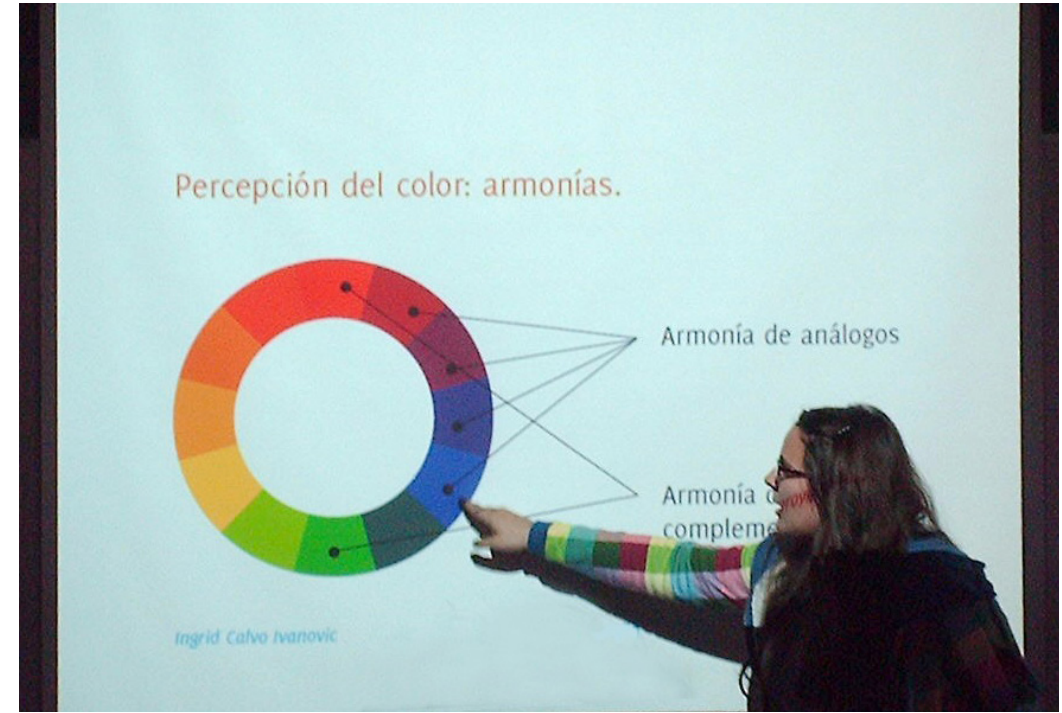

A pesar del cierre de la carrera de diseño en la Universidad de Chile, por la perseverancia de los profesores de la escuela y de algunos alumnos interesados, la carrera de Diseño Gráfico ese mismo año pasa a formar del Instituto Profesional de Santiago (IPS) en la calle Dieciocho, comuna de Santiago, junto a otras carreras que la Universidad de Chile dejó fuera: Bibliotecología, Construcción Civil, Trabajo Social y Cartografía. Más tarde en 1993, debido al éxito alcanzado por el IPS se creó por ley de la República, la Universidad Tecnológica Metropolitana de Santiago (UTEM), donde la Escuela de Diseño del IPS (Ex Universidad de Chile) pasó a formar parte de esta nueva Universidad, y la mención gráfica pasó a denominarse Comunicación Visual (Soto Veragua, 2008).

Con el paso de los años, nace el proyecto de reinstaurar la carrera de Diseño en la Universidad de Chile, en 1995, de la mano de Carlos Rojas Maffioletti y otros dos profesores más: Alejandro Estrada y Guillermo Matus, profesor de la carrera antes de su cierre. Maffioletti reclutó a destacados profesores para formular el regreso de la carrera y sus menciones, lo cual se concretó finalmente al año siguiente, con el ingreso de la primera generación de estudiantes a la reinaugurada cuna de las escuelas de diseño del país (Soto Veragua, 2008), manteniéndose hasta nuestros días. Desde su reapertura, en la Universidad de Chile se obtiene el título de Diseñador Gráfico y posee una duración de diez semestres. En la malla de pregrado, existen dos cursos que entregan contenidos sobre color y son obligatorios: Percepción y Percepción Visual, los cuales están presentes en la malla desde la reapertura de la Escuela en 1996. Uno de los profesores a cargo de estas asignaturas donde se introduce el color, es el Sr. Hugo Rivera Scott, artista visual que se desempeña como profesor desde 1965 (Universidad de Chile, s.f.). Dentro de su experiencia, participó como profesor de color en la Escuela de Arquitectura de la Universidad de Chile de la sede Valparaíso entre 1970 y 1971 (Museo Nacional de Bellas Artes, s.f.). Hoy en día, el profesor Rivera se encuentra a cargo de los cursos mencionados donde el contenido de color es sólo un módulo de muchos otros que se ve en esta asignatura y, por tanto, no están dedicados completamente a este tema. Sin embargo, existió un curso complementario dedicado solamente al color en la escuela de diseño de la Universidad de Chile, llamado "El color en el proceso de Diseño", impartido 
por Arturo Molina desde su apertura hasta el año 2010, donde jubiló (Calvo I., comunicación personal, 9 de diciembre de 2016). Este curso tenía influencias del estudio de color de personajes como Johannes Itten, Faber Birren y Josef Albers (Molina, 2017). Este curso, luego de su jubilación, en los años 2010 y 2011 lo asumió su ayudante Ingrid Calvo, diseñadora gráfica de esta misma escuela y titulada en 2008 , la cual se especializó en temas de color (Calvo, 2016). Posteriormente, como asignatura sucesora a la del profesor Molina, hoy en día, la oferta académica de diseño gráfico ofrece el curso de Color Aplicado que se imparte como asignatura electiva de profundización a cargo de la profesora Calvo desde 2015 (Calvo, 2016). Este curso de carácter teórico-práctico está fundado en aspectos del lenguaje del color, para su aplicación en múltiples ámbitos de las artes y el diseño, el paisaje y el espacio construido, donde el estudiante puede desarrollar y poner en práctica su sensibilidad visual a través de la experiencia, la exploración, comparación y reflexión, tomando decisiones respecto del color en sus proyectos (Calvo, 2016). Teniendo como principales referentes la Sección Didáctica de la Teoría del Color de J.W.V. Goethe (1749-1832) y su enfoque fenomenológico, junto con la repercusión y herencia de este mismo texto que realizaron en el contexto de la Bauhaus: Johannes Itten, Paul Klee, Vasily Kandinski y Josef Albers (Calvo, 2016). Además, posee como referente otros cursos de color como el de Eduardo Vilches, quien fue alumno de Albers y maestro de la profesora Calvo, y que ha sido impartido por muchos años en la Pontificia Universidad Católica de Santiago, y, también, los ejercicios cromáticos de Cornelia Vargas Koch (Calvo, 2016), que ocupan como base una retícula para componer.

\section{Conclusiones}

La educación del color en la EAA, se vio muy influenciada por las artes plásticas debido al cauce natural que tuvo su origen dentro de la Escuela de Bellas Artes y, también, por los años en que estuvo estrechamente en relación con ésta. Esto significó que la mayoría de los docentes y profesionales que se formaron en la EAA y que posteriormente participaron en la gestación del diseño gráfico en la Universidad de Chile tuvieran esta noción del color. Este enfoque mencionado de la educación del color desde las bellas artes contempla un rol más decorativo y estético, sin embargo, las necesidades de la nueva disciplina proyectual llevaron a que profesores del plantel, como Arturo Molina, se instruyeran en dicho tema y que la formación en la EAA no le otorgaban las habilidades necesarias para abordarlo conforme a los requerimientos de este campo de estudio emergente y, quizás, esto refiere al rol perceptual y funcional, además del ya mencionado rol estético en la comunicación visual. De esta forma, el conocimiento sobre color se fue complementando a través de los años con los aportes de profesores claves que fueron insertando contenidos relevantes en los programas de asignaturas sobre color en esta nueva disciplina, el diseño. Por tanto, docentes como Arturo Molina e Ingrid Calvo que se especializaron en este tema, han contribuido de manera significativa a la formación de estudiantes de diseño en la Universidad de Chile debido a que han desarrollado cursos dedicados a tratar específicamente el fenómeno del color.

Este artículo sólo hizo una pequeña reseña histórica a los orígenes del diseño gráfico en Chile y su educación en el color. Sería de gran importancia profundizar este estudio. 


\section{Referencias bibliográficas}

Biblioteca Nacional de Chile (s.f.). "Escuela de Artes y Oficios", en: La educación técnica en Chile. Memoria Chilena. Recuperado el 07/08/2016 de http://www. memoriachilena.cl/602/w3-article-95225.html

Biblioteca Nacional de Chile (s.f.). "primeros talleres de oficios artísticos en Chile", en: Arte en Chile durante la Colonia. Memoria Chilena. Recuperado el 03/08/2016 de http://www.memoriachilena.cl/602/w3-article-92341.html

Biblioteca Nacional de Chile (s.f.). Arte en Chile durante la Colonia. Memoria Chilena. Recuperado el 05/08/2016 de http://www.memoriachilena.cl/602/w3-article-100575.html

Biblioteca Nacional de Chile (s.f.). La educación técnica en Chile. Memoria Chilena. Recuperado el 06/08/2016 de http://www.memoriachilena.cl/602/w3-article-682.html

Biblioteca Nacional de Chile (s.f.). La Universidad de Chile (1842-1990). Memoria Chilena. Recuperado el 06/8/2016 de http://www.memoriachilena.cl/602/ w3-article-720.html

Biblioteca Nacional de Chile (s.f.). Orígenes de la educación artística escolar en Chile, en: Educación artística escolar. Memoria Chilena. Recuperado el 02/08/2016 de http://www.memoriachilena.cl/602/w3-article-93407.html

Biblioteca Nacional de Chile (s.f.). Pontificia Universidad Católica (1888-). Memoria Chilena. Recuperado el 08/08/2016 de http://www.memoriachilena.cl/602/ w3-article-776.html

Biblioteca Nacional de Chile (s.f.). Primeras universidades en Chile (1622-1843). Memoria Chilena. Recuperado el 03/08/2016 de http://www.memoriachilena.cl/602/ w3-article-716.html

Castillo Espinoza, E. Editor (2010). Artesanos, Artistas, Artífices. La Escuela de Artes Aplicadas de La Universidad de Chile 1928-1968. Santiago, Chile: Ocho Libros.

DdD. Departamento de Diseño. (s.f.). Hugo Rivera-Scott. Recuperado el o9/o9/2017 de http://ddd.uchilefau.cl/ portfolio/hugo-rivera-scott/

Dussaillant Christie, J. (2005). Pedro Álvarez Caselli: Historia del Diseño Gráfico en Chile. Historia (Santiago), 38(1), 167-169.

Facultad de Arquitectura y Urbanismo. Universidad de Chile. (s.f.). Historia. Recuperado el o8/09/2017 de http://www.fau.uchile.cl/facultad/presentacion/63270/historia

Gage, J. (1993). Colory Cultura: Práctica y significado del color de la Antigüedad a la Abstracción. Londres, UK: Ediciones Siruela.
Museo de Arte Precolombino. (s.f.). Pueblos Originarios de Chile. Mapuches. Recuperado el 05/10/2016 de a http://www.precolombino.cl/culturas-americanas/ pueblos-originarios-de-chile/mapuche/\#/arte/

Museo Nacional de Bellas Artes. (s.f.). Hugo Rivera. Artistas Visuales Chilenos. Recuperado el 29/10/2017 de http://www.artistasvisualeschilenos.cl/658/w3-article-39538.html

Museo Nacional de Bellas Artes. (s.f.). José Perotti Ronzzoni. Artistas Visuales Chilenos. Recuperado el 08/09/2016 de http://www.artistasvisualeschilenos. cl/658/w3-article-39907.html

Pereira, E. (1965). Historia del Arte en el Reino de Chile. Santiago: Universidad de Chile.

Pontificia Universidad Católica de Chile. Escuela de Arte UC. Historia. Recuperado el o8/08/2016 de http://escuelaarte.uc.cl/index.php/escuela/historia

Pontificia Universidad de Católica de Chile. Arquitectura UC. Historia. Recuperado el ০8/08/2016 de http:// arquitectura.uc.cl/index.php/lo-contador/campus/ historia

Soto Veragua, J. (2008). Raíces, troncos y Ramas del Diseño Gráfico en Chile. Santiago, Chile: Editorial El Árbol Azul Ltda.

Universidad de Chile (s.f.). Historia de la Facultad de Artes. Agosto 07, 2016. Sitio Web: http://www.artes. uchile.cl/facultad/presentacion/40911/historia 